\title{
A systematic review and meta-analysis of the genetic characterization of human echinococcosis in Iran, an endemic country
}

\author{
Abolghasem Siyadatpanah ${ }^{1,2}$, Davood Anvari ${ }^{3,4}$, Amir Emami Zeydi ${ }^{5}$, Seyed Abdollah Hosseini ${ }^{3}$, \\ Ahmad Daryani ${ }^{6}$, Shahabeddin Sarvi ${ }^{6}$, Christine M. Budke ${ }^{7}$, Reza Esmaeelzadeh Dizaji ${ }^{8}$, \\ Mohammad Ali Mohaghegh ${ }^{9}$, Mohammad Hasan Kohansal ${ }^{10}$, Samira Dodangeh ${ }^{3}$, \\ Reza Saberi ${ }^{3}$, Shirzad Gholami ${ }^{6}$ \\ ${ }^{1}$ Ferdows Paramedical School, Birjand University of Medical Sciences, Birjand, Iran; ${ }^{2}$ Infectious Diseases Research Center, Birjand University \\ of Medical Sciences, Birjand, Iran; ${ }^{3}$ Department of Parasitology, Student Research Committee, Toxoplasmosis Research Center, Mazandaran \\ University of Medical Science, Sari, Iran; ${ }^{4}$ Department of Microbiology and Immunology, School of Medicine, Iranshahr University of Medical \\ Sciences, Iranshahr, Iran; ${ }^{5}$ Department of Medical-Surgical Nursing, Nasibeh School of Nursing and Midwifery, Mazandaran University of \\ Medical Sciences, Sari, Iran; ${ }^{6}$ Department of Parasitology, Toxoplasmosis Research Center, Mazandaran University of Medical Sciences, Sari, \\ Iran; ${ }^{7}$ Department of Veterinary Integrative Biosciences, College of Veterinary Medicine Biomedical Sciences, Texas A\&M University, College \\ Station, TX, USA; ${ }^{8}$ Department of Poultry Disease, Faculty of Veterinary Medicine, University of Tehran, Tehran, Iran; ${ }^{9}$ Health Sciences Research \\ Center, Department of Laboratory Sciences, School of Paramedical Sciences, Torbat Heydariyeh University of Medical Sciences, Torbat \\ Heydariyeh, Iran; ${ }^{10}$ School of Medicine, Bam University of Medical Sciences, Bam, Iran
}

\begin{abstract}
Human echinococcosis is an infectious disease caused by tapeworms belonging to the species Echinococcus. This parasite has a worldwide distribution and is considered a neglected tropical disease by the World Health Organization. Due to the diversity of Echinococcus spp. hosts, as well as variation in geographical, climatic, and socio-ethnic conditions, the question of the strains or genotypes of Echinococcus spp. that are involved in human infections is important. The aim of this study was to provide a summary of the available data on genotypes of Echinococcus obtained from the Iranian population. Four international databases (PubMed, Scopus, Science Direct, and Web of Science) and 4 Persian databases (Magiran, Scientific Information Database, Iran Medex, and IranDoc) were searched for cross-sectional studies that reported the genotypes of Echinococcus spp. in human echinococcosis cases using molecular methods in Iran through July 2018. The Newcastle-Ottawa Scale was used to assess the quality of the selected studies. A total of 559 cases of human cystic echinococcosis were reported in the 21 included articles. The majority of cases belonged to genotype G1 (89.2\%; 95\% confidence interval [CI], 80.1 to 95.8), genotype G6 (8.2\%; $95 \%$ CI, 2.8 to 15.9), and genotype G3 (2.3\%; 95\% CI, 1.1 to 3.9). Since genotype G1 of Echinococcus appears to be the most prevalent genotype affecting humans in Iran, disease control initiatives aimed at sheep intermediate hosts may be the most beneficial. In addition, educational programs and serological screening in individuals may help reduce the national impact of the disease.
\end{abstract}

KEY WORDS: Cystic echinococcosis, Genotype, Human, Systematic review, Meta-analysis, Iran

\section{Correspondence: Shirzad Gholami}

Department of Parasitology, Toxoplasmosis Research Center, Mazandaran University of Medical Sciences, Km 18 Khazar Abad, Sari, Iran

E-mail: sgholami200@gmail.com

Received: Apr 30, 2019 / Accepted: Jun 15, 2019 / Published: Jun 15, 2019

This article is available from: http://e-epih.org/

(C) This is an open-access article distributed under the terms of the Creative Commons Attribution License (http://creativecommons.org/licenses/by/4.0/), which permits unrestricted use, distribution, and reproduction in any medium, provided the original work is properly cited.

(C) 2019, Korean Society of Epidemiology

\section{INTRODUCTION}

Human echinococcosis is an infectious disease caused by tapeworms belonging to the species Echinococcus. This parasitic zoonosis has a worldwide distribution and is considered a neglected tropical disease by the World Health Organization [1,2]. Adult worms live in the small intestine of carnivores (for example, dogs, jackals, foxes, and wolves) and the eggs are excreted through the feces of these animals. Echinococcus eggs are ingested by intermediate hosts, including ruminants, camels, horses, and pigs, where the parasite forms metacestode cysts [3,4]. Humans can also act as 
aberrant intermediate hosts through direct infection (via direct contact with an infected definitive host) or indirect infection (via ingesting contaminated food or water) $[4,5]$.

The 2 major species of medical and public health importance are Echinococcus granulosus and Echinococcus multilocularis, which cause cystic echinococcosis (CE) and alveolar echinococcosis, respectively. Both are serious and severe diseases, the latter especially so, with high case fatality rates and a poor prognosis if managed incorrectly. Based on phylogenetic studies, E. granulosus sensu lato consists of 10 genotypes or group complexes, which include $E$. granulosus sensu stricto (genotypes G1-G3), Echinococcus equinus (genotype G4), Echinococcus ortleppi (genotype G5), Echinococcus canadensis (genotypes G6-G8, G10), and Echinococcus felidis (lion strain). All of these genotypes, except genotype G4, have been shown to cause human disease [6,7]. CE can affect any part of the body, but the liver and lungs are the most commonly affected organs. Clinical symptoms vary depending on the cyst's size and anatomical location, with many patients remaining asymptomatic for years or never developing symptoms [8]. In addition to its health consequences, $\mathrm{CE}$ also has an economic impact on affected communities and regions. The estimated global economic loss due to human infections was estimated to be US\$200-800 million, annually [9].
$\mathrm{CE}$ is endemic in Iran and the reported prevalence of Echinococcus spp. infection in Iranian dogs ranges from 5\% to 49\%. The prevalence of CE in Iranian sheep and camels has been reported to be as high as $88 \%$ and $64 \%$, respectively [10]. The frequency of CE detected in surgical cases ranges from 1.1 to 18.3 per 100,000 population depending on region $[2,10]$. Molecular identification of locally circulating Echinococcus genotypes is important for gaining insights into parasite prevalence and disease ecology in the various regions. Molecular identification also plays an important role in the development of control strategies, including the identification of locally important definitive and intermediate hosts $[8$, 11-14]. Numerous studies have been performed on genotyping of E. granulosus from Iran. However, no study has systematically analyzed this information. The aim of this systematic review was to provide a summary of the available data on Echinococcus genotypes obtained from the Iranian population.

\section{MATERIALS AND METHODS}

\section{Search strategy}

Four international databases (PubMed, Scopus, Science Direct and Web of Science) and 4 Persian databases (Magiran, Scientific
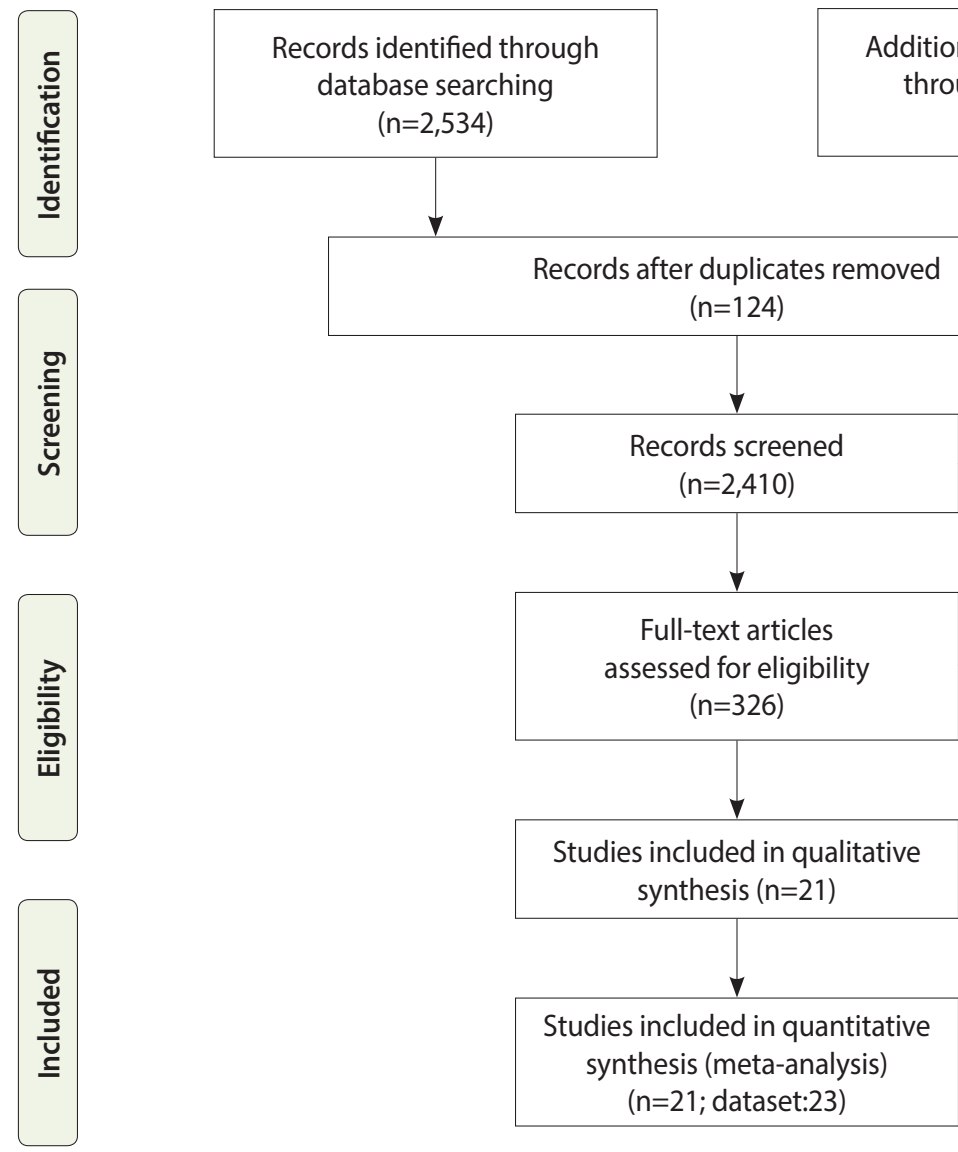

Figure 1. Flow diagram of the systematic review and meta-analysis process. 
Information Database, Iran Medex, and IranDoc) were searched for articles (full text) published online in the English and Persian languages from January 1999 to July 2018. The keywords, used alone or in combination, were "cystic echinococcosis," "Echinococcus granulosus," "hydatid cyst," "hydatid disease," "hydatidosis," "hydatidoses," "genotype," "genetic variation," and "Iran". In addition, to avoid missing any articles, the references of the identified articles were carefully checked.

The literature search identified 2,534 papers, of which 124 were excluded as duplicates. After a primary screening of the titles and abstracts, an additional 2,084 studies were excluded. After reading the full text of the remaining articles, 305 other papers were eliminated. Four studies were added after reviewing the references of the identified papers. Finally, 21 eligible studies were identified for inclusion in the systematic review (Figure 1 and Table 1) [15-35].

\section{Inclusion and exclusion criteria}

A paper was included if it fulfilled the following criteria: a crosssectional study that investigated human echinococcosis by any molecular diagnostic method that detected genotypes of Echinococcus spp. in Iran. Duplicate manuscripts, case reports or case series, letters to the editor, review articles, animal studies, non-molecular studies, and articles with insufficient information were excluded.

\section{Data extraction}

After completing the search, the chosen articles were independently assessed by 2 authors (AS \& SG). All duplicate and irrelevant articles were excluded after evaluating their titles, abstracts, and full texts. Any disagreements between the 2 authors were resolved by consultation with another author (DA). The characteristics of each manuscript were extracted using a predesigned datacollection spreadsheet. The recorded information included the first author, year of publication, study location, study design, number of total collected samples, and number of samples for each identified genotype.

\section{Quality assessment}

In the current study, the Newcastle-Ottawa Scale was utilized to assess the quality of cross-sectional studies (low quality, <3.50; moderate quality, 3.60-5.25; and high quality, 5.26-7.00) [36]. Only articles with at least an acceptable quality $(>3.50)$ were included in the meta-analysis.

\section{Statistical analysis}

The meta-analysis was performed using StatsDirect (https:// www.statsdirect.com/). The standard error for each study estimate was calculated from a binomial distribution formula. We pooled each study estimate using a random-effects model to obtain an

Table 1. Basic characteristics were identified in the studies ${ }^{1}$

\begin{tabular}{|c|c|c|c|c|}
\hline Study & Province & Genotypes & Human CE (n) & $\mathrm{QA}$ \\
\hline Harandi et al., 2002 [25] & Kerman & G1, G6 & 36 & 7 \\
\hline Kia et al., 2010 [26] & Isfahan & G1 & 30 & 7 \\
\hline Shahnazi et al., 2011 [21] & Isfahan & G1, G6 & 31 & 7 \\
\hline Gholami et al., 2012 [15] & Golestan & G1, G6 & 30 & 6 \\
\hline Sadjjadi et al., 2013 [28] & Khuzestan & G6 & 3 & 6 \\
\hline Pezeshki et al., 2013 [27] & Ardabil & G1, G3 & 11 & 7 \\
\hline Dousti et al., 2013 [22] & Ilam & G1 & 4 & 7 \\
\hline Khademvatan et al., 2013 [30] & Khuzestan & G1 & 5 & 6 \\
\hline Vahedi et al., 2014 [32] & East Azerbaijan & G1 & 55 & 7 \\
\hline Nikmanesh et al., 2014 [18] & Tehran & G1, G3, G6 & 47 & 6 \\
\hline Rostami et al., 2015 [20] & Alborz & G1, G6 & 7 & 7 \\
\hline Rostami et al., 2015 [20] & Tehran & G1, G6 & 70 & 7 \\
\hline Rostami et al., 2015 [20] & Kerman & $\mathrm{G} 1, \mathrm{G} 2, \mathrm{G} 3, \mathrm{G} 6$ & 48 & 6 \\
\hline Spotin et al., 2015 [35] & Semnan & G1, G6 & 7 & 7 \\
\hline Farhadi et al., 2015 [33] & Zanjan & G1 & 9 & 7 \\
\hline Shamsi et al., 2015 [16] & Ilam & G1 & 10 & 7 \\
\hline Sharbatkhori et al., 2016 [17] & Golestan & G1 & 4 & 7 \\
\hline Kheirandish et al., 2017 [23] & Lorestan & $\mathrm{G} 1, \mathrm{G} 3$ & 26 & 7 \\
\hline Karamian et al., 2017 [31] & South Khorasan & G1, G6 & 9 & 7 \\
\hline Arbabi et al., 2017 [19] & Markazi & G1 & 15 & 7 \\
\hline Jafarzadeh et al., 2018 [24] & North Khorasan & G1 & 60 & 7 \\
\hline Gorgani-Firouzjaee et al., 2018 [29] & Mazandaran & G1 & 6 & 7 \\
\hline Jafari et al., 2018 [34] & Isfahan & G1, G3, G6 & 50 & 6 \\
\hline
\end{tabular}

CE, cystic echinococcosis; QA, quality assessment.

${ }^{1}$ Type of studies were cross-sectional study. 
Proportion meta-analysis plot (random effects)

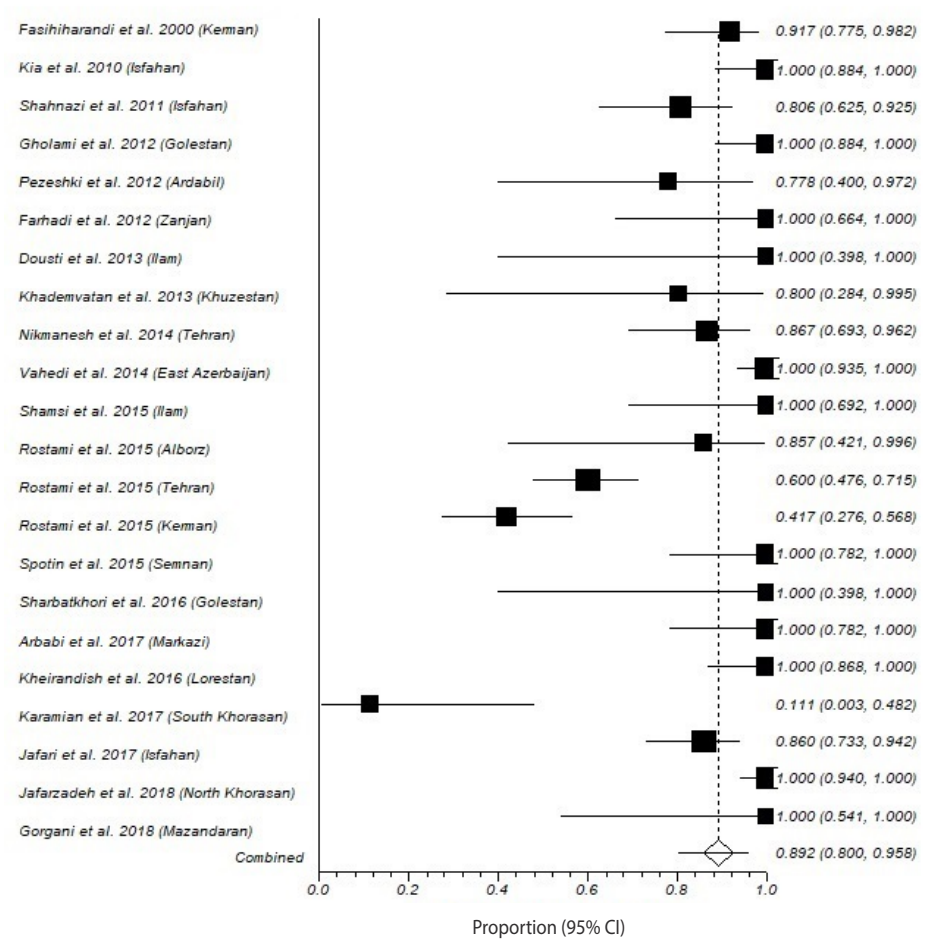

Proportion meta-analysis plot (random effects)

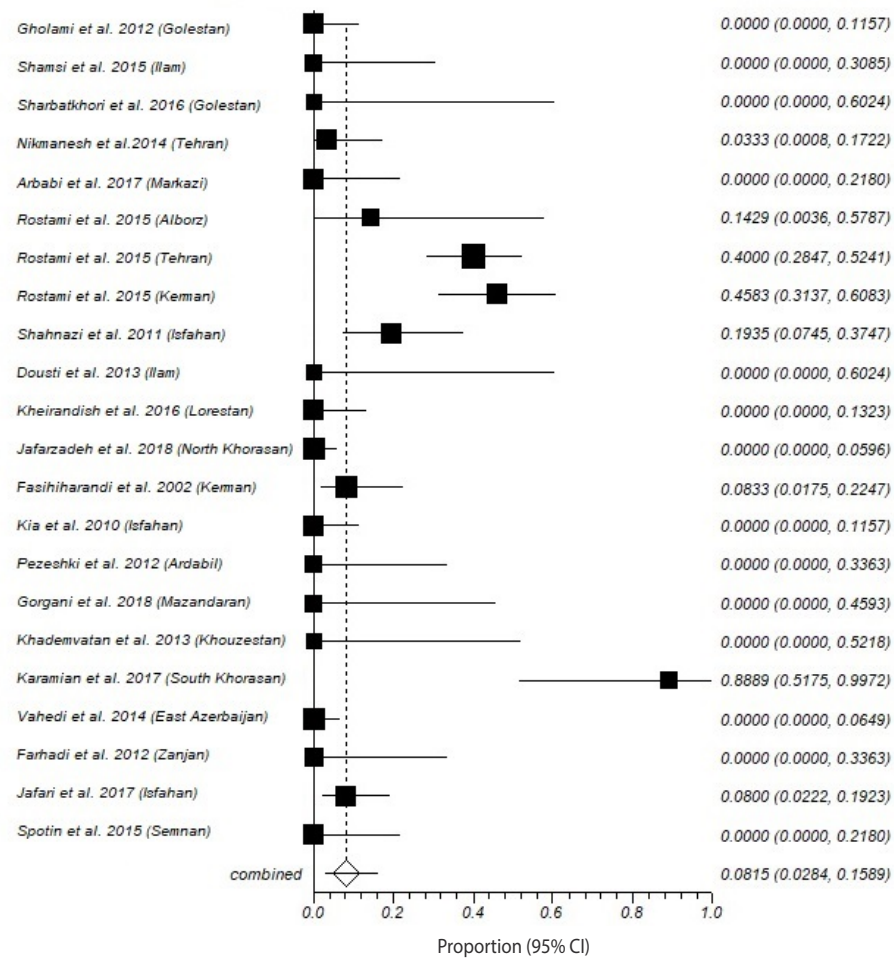

B

Figure 2. Forest plot of the proportion of cystic echinococcosis cases due to Echinococcus granulosus genotypes (A) G1, (B) G6, and (C) G3 in Iran. $\mathrm{Cl}$, confidence interval.

(Continued to the next page) 
Proportion meta-analysis plot (random effects)

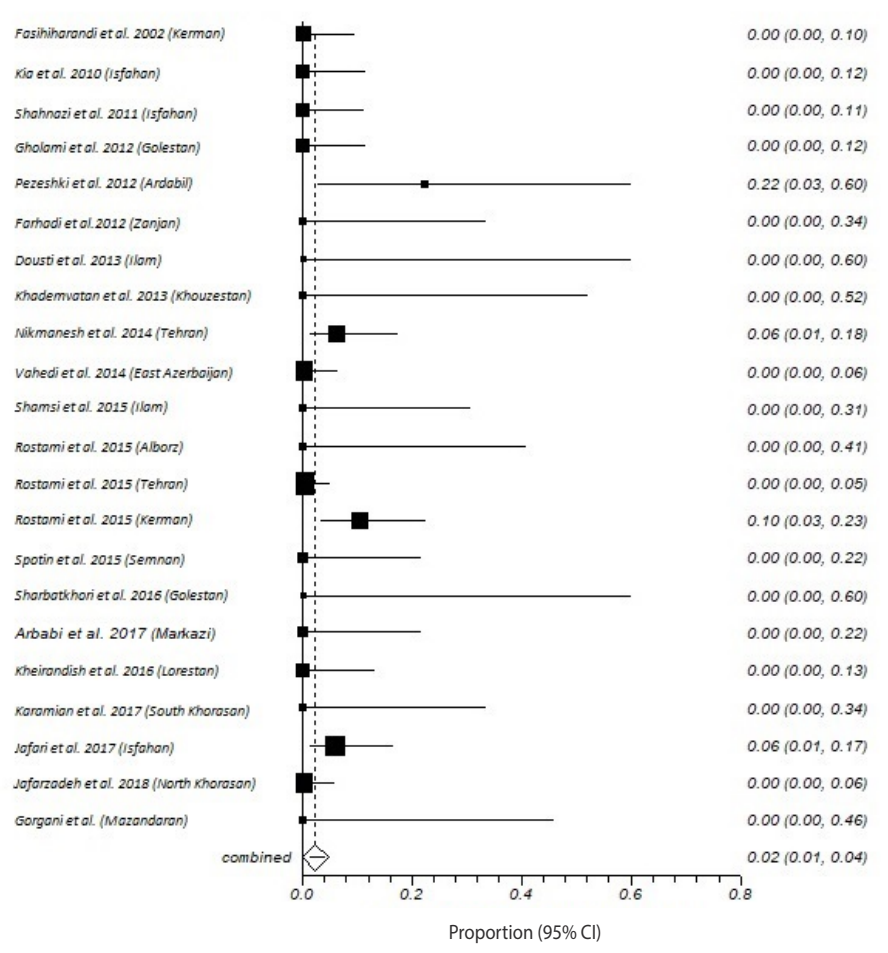

Figure 2. Continued.

Table 2. Prevalence, publication bias, and heterogeneity of genotypes of human echinococcosis in Iran

\begin{tabular}{lcccccccc}
\hline $\begin{array}{c}\text { Geno- } \\
\text { type }\end{array}$ & $\begin{array}{c}\text { Prevalence, } \% \\
(95 \% \mathrm{Cl})\end{array}$ & $\begin{array}{c}\text { Cochran } \\
\mathrm{Q}\end{array}$ & df & $\mathrm{I}^{2}(\%)$ & $\mathrm{p}$-value & $\begin{array}{c}\text { Egger } \\
\text { bias }\end{array}$ & p-value \\
\hline G1 & $89.2(80.1,95.8)$ & 188.9 & 21 & 88.9 & $<0.001$ & -2.3 & 0.011 \\
G6 & $8.2(2.8,15.9)$ & 164.9 & 21 & 87.3 & $<0.001$ & -1.4 & 0.025 \\
G3 & $2.3(1.1,3.9)$ & 26.8 & 21 & 21.6 & 0.178 & 0.4 & 0.086
\end{tabular}

$\mathrm{Cl}$, confidence interval; $\mathrm{df}$, degree of freedom.

overall summary estimate of each Echinococcus isolate genotype (G1, G2, G3, and G6), as well as the accompanying 95\% confidence intervals (CIs). Heterogeneity between the results was assessed based on the Q test and the $\mathrm{I}^{2}$ indicator [37-39]. In addition, the Egger test was used to investigate the presence of publication bias.

\section{Ethics statement}

This study is a systematic review and does not deal with human participants.

\section{RESULTS}

Data were available from 15 Iranian provinces. The included studies demonstrated wide variation in the proportion of genotypes identified in individual studies.
A total of 559 cases of human CE were reported in the 21 included studies. The majority of cases belonged to genotype G1 (89.2\%; 95\% CI, 80.1 to 95.8$)$, genotype G6 (8.2\%; 95\% CI, 2.8 to $15.9)$, and genotype G3 (2.3\%; 95\% CI, 1.1 to 3.9$)$, respectively (Figure 2 and Table 2). Since only a single CE case attributed to the genotype G2 has been identified in Iran, this genotype was not included in the meta-analysis (Table 1). The Egger regression test indicated that publication bias was significant for genotypes G1 and G6, but not for genotype G3 (Table 2).

\section{DISCUSSION}

$\mathrm{CE}$ is an emerging neglected disease and a public health concern in the Middle East that results in substantial economic losses $[40,41]$. Molecular surveys are considered to be the gold standard for the differential diagnosis of human echinococcosis. This method is the only way to identify the species of Echinococcus (genotypes). In contrast to the widespread use of serological and imaging tests, molecular assays are rarely used for clinical diagnoses, perhaps due to the delay in diagnosis. Making a correct diagnosis is an essential prerequisite for the effective treatment of this disease, as misdiagnosis or unclear diagnosis could eventually lead to relapse or metastasis, even after surgery. The genetic characterization of E. granulosus using polymerase chain reaction-based methods has yielded a deeper understanding of its global epidemiology 
[42]. At present, 4 E. granulosus genotypes (G1, G2, G3, and G6) have been identified in human CE patients in Iran [43]. Similar to our study, a systematic review of human cases worldwide showed that $72.9 \%$ were caused by E. granulosus genotypes (G1), $12.2 \%$ by G6, $9.6 \%$ by G7, $3.2 \%$ by G3, $1.0 \%$ by G5, $0.8 \%$ by $\mathrm{G} 2,0.2 \%$ by $\mathrm{G} 10$, and $0.1 \%$ by G8 [44].

Worldwide, the G1 genotype is responsible for the majority of human CE cases [42,44], and this genotype is largely maintained in a domestic sheep/dog life cycle. Cysts found in older sheep are often fertile $[45,46]$. While human cases from Pakistan and Afghanistan have largely involved the G1 genotype, more diverse $\mathrm{CE}$ genotypes have been isolated from human subjects in Turkey and Iraq [47].

In the present study, genotype G6 (camel strain) accounted for $8.15 \%$ of isolates collected from Golestan, Tehran, Alborz, Kerman, Isfahan, Khuzestan, South Khorasan, and Semnan Provinces. Due to the special weather conditions (heat and aridity) required for breeding camels in Iran, this animal is only raised in a few provinces, including Khorasan Razavi, South Khorasan, Semnan, Sistan and Baluchestan, and Yazd Provinces. For this reason, this genotype has not been observed in all provinces of Iran [48]. Genotype G6 appears to be the second most prevalent E. granulosus genotype in Iran, which is comparable to recent information from South American countries [44]. This genotype has been reported in a variety of countries, including Brazil, Kenya, Turkey, China, and southeastern Romania [49].

The results of this systematic review and meta-analysis show that genotype G3 (buffalo strain) was found in 4 provinces of Iran, including Isfahan, Ardabil, Kerman, and Tehran Provinces. This genotype has also been reported in humans in Italy, Romania, Turkey, India, Tunisia, and Brazil [47]. This genotype has also been reported in sheep, goat, cattle, and pigs in Pakistan, Italy, and Greece [50,51].

The G2 strain was found in 1 case from Kerman Province [20]. This is not unexpected, since one of the main intermediate hosts of this genotype (Tasmanian sheep) are not found in Iran. However, in 2012, Parsa et al. [52] identified this genotype, for the first time, from a dog in Iran. The absence of genotype G7 (pig strain) in human cases in Iran may be partially ascribed to the lack of pig breeding in Islamic countries.

This systematic review has the following limitations: (1) none of the included studies evaluated variables such as patients' age, sex, and type of immunity, (2) the studies analyzed herein contained insufficient information about patients' condition or the severity of the disease, and (3) the included studies had no uniform sample size. These limitations may have significant implications for our understanding of the epidemiological aspects of this infection among humans in Iran. In addition, many questions remain to be answered in future investigations.

\section{CONCLUSION}

Since genotype G1 appears to be the most prevalent genotype affecting the Iranian population, disease control initiatives aimed at sheep intermediate hosts may be the most beneficial. Moreover, educational programs and serological screening in the population may help to reduce the national impact of human echinococcosis. Further studies are needed to describe the comprehensive epidemiology of this disease at a national level in Iran.

\section{CONFLICT OF INTEREST}

The authors have no conflicts of interest to declare for this study.

\section{ACKNOWLEDGEMENTS}

The authors thank all their colleagues working at the Toxoplasmosis Research Center (TRC) of Mazandaran University of Medical Sciences, Sari, Iran.

\section{AUTHOR CONTRIBUTIONS}

Conceptualization: AS, SG. Data curation: AS, DA, AEZ, SAH, $\mathrm{AD}, \mathrm{SS}, \mathrm{CMB}, \mathrm{RED}, \mathrm{MAM}, \mathrm{MHK}, \mathrm{SD}, \mathrm{RS}$. Formal analysis: AS, SAH, DA, AEZ. Methodology: AS, DA, AEZ, SG. Project administration: AS, SG. Visualization: DA, SAE. Writing - original draft: AS, DA, AEZ, SG. Writing - review \& editing: AS, DA, AEZ, SAH, AD, SS, CMB, RED, MAM, MHK, SD, RS, SG.

\section{ORCID}

Abolghasem Siyadatpanah: https://orcid.org/0000-0003-31725939; Davood Anvari: https://orcid.org/0000-0003-1021-4347; Amir Emami Zeydi: https://orcid.org/0000-0001-8984-3298; Seyed Abdollah Hosseini: https://orcid.org/0000-0002-7711-4714; Ahmad Daryani: https://orcid.org/0000-0001-8571-5803; Shahabeddin Sarvi: https://orcid.org/0000-0002-3412-1033; Christine M. Budke: https://orcid.org/0000-0002-4750-0905; Reza Esmaeelzadeh Dizaji: https://orcid.org/0000-0001-9044-1659; Mohammad Ali Mohaghegh: https://orcid.org/0000-0001-8301-5256; Mohammad Hasan Kohansal: https://orcid.org/0000-0001-9177-1182; Samira Dodangeh: https://orcid.org/0000-0002-9450-938X; Reza Saberi: https://orcid. org/0000-0002-7906-7034; Shirzad Gholami: https://orcid.org/00000003-2429-7702

\section{REFERENCES}

1. Ito A, Budke CM. The echinococcoses in Asia: the present situation. Acta Trop 2017;176:11-21.

2. Fasihi Harandi M, Budke CM, Rostami S. The monetary burden of cystic echinococcosis in Iran. PLoS Negl Trop Dis 2012;6:e1915.

3. Otero-Abad B, Torgerson PR. A systematic review of the epidemiology of echinococcosis in domestic and wild animals. PLoS Negl Trop Dis 2013;7:e2249.

4. Cringoli G, Rinaldi L, Musella V, Veneziano V, Maurelli MP, Di Pietro F, et al. Geo-referencing livestock farms as tool for studying cystic echinococcosis epidemiology in cattle and water buffaloes 
from southern Italy. Geospat Health 2007;2:105-111.

5. Kebede N, Mitiku A, Tilahun G. Hydatidosis of slaughtered animals in Bahir Dar Abattoir, Northwestern Ethiopia. Trop Anim Health Prod 2009;41:43-50.

6. Nakao M, Lavikainen A, Yanagida T, Ito A. Phylogenetic systematics of the genus Echinococcus (Cestoda: Taeniidae). Int J Parasitol 2013;43:1017-1029.

7. Thompson RC. Biology and systematics of Echinococcus. Adv Parasitol 2017;95:65-109.

8. Eckert J, Gemmell MA, Meslin FX, Pawłowski ZS. WHO/OIE manual on echinococcosis in humans and animals: a public health problem of global concern; 2001 [cited 2019 Jul 9]. Available from: https://apps.who.int/iris/bitstream/handle/10665/42427/929044522X. pdf? sequence $=1$ \&isAllowed $=y$.

9. Cerda JR, Buttke DE, Ballweber LR. Echinococcus spp. Tapeworms in North America. Emerg Infect Dis 2018;24:230-235.

10. Rokni MB. Echinococcosis/hydatidosis in Iran. Iran J Parasitol 2009;4:1-16.

11. Odongo DO, Tiampati CM, Mulinge E, Mbae CK, Bishop RP, Zeyhle E, et al. Prevalence and genotyping of Echinococcus granulosus in sheep in Narok County, Kenya. Parasitol Res 2018;117:20652073.

12. Nakao M, McManus DP, Schantz PM, Craig PS, Ito A. A molecular phylogeny of the genus Echinococcus inferred from complete mitochondrial genomes. Parasitology 2007;134:713-722.

13. Craig PS, McManus DP, Lightowlers MW, Chabalgoity JA, Garcia $\mathrm{HH}$, Gavidia CM, et al. Prevention and control of cystic echinococcosis. Lancet Infect Dis 2007;7:385-394.

14. Anvari D, Saadati D, Nabavi R, Alipour Eskandani M. Epidemiology and molecular prevalence of toxoplasma gondii in cattle slaughtered in Zahedan and Zabol Districts, South East of Iran. Iran J Parasitol 2018;13:114-119.

15. Gholami Sh, Sosari M, Fakhar M, Sharif M, Daryani A, Hashemi $\mathrm{M}$, et al. Molecular characterization of Echinococcus granulosus from hydatid cysts isolated from human and animals in Golestan Province, North of Iran. Iran J Parasitol 2012;7:8-16.

16. Shamsi M, Dalimi A, Khosravi A, Ghafarifar F. Determination of genotype isolates of human and sheep hydatid cyst in Ilam. J Ilam Univ Med Sci 2015;23:111-119 (Persian).

17. Sharbatkhori M, Tanzifi A, Rostami S, Rostami M, Fasihi Harandi M. Echinococcus granulosus sensu lato genotypes in domestic livestock and humans in Golestan Province, Iran. Rev Inst Med Trop Sao Paulo 2016;58:38.

18. Nikmanesh B, Mirhendi H, Ghalavand Z, Alebouyeh M, Sharbatkhori M, Kia E, et al. Genotyping of Echinococcus granulosus isolates from human clinical samples based on sequencing of mitochondrial genes in Iran, Tehran. Iran J Parasitol 2014;9:20-27.

19. Arbabi M, Pirestani M, Delavari M, Hooshyar H, Abdoli A, Sarvi S. Molecular and morphological characterizations of Echinococcus granulosus from human and animal isolates in Kashan, Markazi Province, Iran. Iran J Parasitol 2017;12:177-187.

20. Rostami S, Shariat Torbaghan S, Dabiri S, Babaei Z, Ali Mohammadi M, Sharbatkhori M, et al. Genetic characterization of Echi- nococcus granulosus from a large number of formalin-fixed, paraffin-embedded tissue samples of human isolates in Iran. Am J Trop Med Hyg 2015;92:588-594.

21. Shahnazi M, Hejazi H, Salehi M, Andalib AR. Molecular characterization of human and animal Echinococcus granulosus isolates in Isfahan, Iran. Acta Trop 2011;117:47-50.

22. Dousti M, Abdi J, Bakhtiyari S, Mohebali M, Mirhendi Sh, Rokni M. Genotyping of hydatid cyst isolated from human and domestic animals in Ilam Province, Western Iran using PCR-RFLP. Iran J Parasitol 2013;8:47-52.

23. Kheirandish F, Mahmoudvand H, Ahmadinejad M, Karimi Rouzbahani A. Genetic characterization of human-derived hydatid cysts of Echinococcus granulosus in Lorestan Province, Western Iran. Trop Biomed 2017;34:863-869.

24. Jafarzadeh F, Raeghi S, Abad M, Vafaee F, Tabaei SJ, Jafarzadeh Hesari M. Molecular and phylogenetic analysis of human hydatid cysts. JNKUMS 2018;9:15-19 (Persian).

25. Harandi MF, Hobbs RP, Adams PJ, Mobedi I, Morgan-Ryan UM, Thompson RC. Molecular and morphological characterization of Echinococcus granulosus of human and animal origin in Iran. Parasitology 2002;125:367-373.

26. Kia EB, Rahimi H, Sharbatkhori M, Talebi A, Fasihi Harandi M, Mirhendi H. Genotype identification of human cystic echinococcosis in Isfahan, central Iran. Parasitol Res 2010;107:757-760.

27. Pezeshki A, Akhlaghi L, Sharbatkhori M, Razmjou E, Oormazdi $\mathrm{H}$, Mohebali M, et al. Genotyping of Echinococcus granulosus from domestic animals and humans from Ardabil Province, Northwest Iran. J Helminthol 2013;87:387-391.

28. Sadjjadi SM, Mikaeili F, Karamian M, Maraghi S, Sadjjadi FS, Shariat-Torbaghan S, et al. Evidence that the Echinococcus granulosus G6 genotype has an affinity for the brain in humans. Int J Parasitol 2013;43:875-877.

29. Gorgani-Firouzjaee T, Kalantrai N, Ghaffari S, Alipour J, Siadati S. Genotype characterization of livestock and human cystic echinococcosis in Mazandaran Province, Iran. J Helminthol 2018;93:255259.

30. Khademvatan S, Yousefi E, Rafiei A, Rahdar M, Saki J. Molecular characterization of livestock and human isolates of Echinococcus granulosus from south-west Iran. J Helminthol 2013;87:240-244.

31. Karamian M, Haghighi F, Hemmati M, Taylor WR, Salehabadi A, Ghatee MA. Heterogenity of Echinococcus canadensis genotype 6 - the main causative agent of cystic echinococcosis in Birjand, Eastern Iran. Vet Parasitol 2017;245:78-85.

32. Vahedi A, Mahdavi M, Ghazanchaei A, Shokouhi B. Genotypic characteristics of hydatid cysts isolated from humans in East Azerbaijan Province (2011-2013). J Anal Res Clin Med 2014;2:152-157.

33. Farhadi M, Fazaeli A, Haniloo A. Genetic characterization of livestock and human hydatid cyst isolates from northwest Iran, using the mitochondrial cox1 gene sequence. Parasitol Res 2015;114: 4363-4370.

34. Jafari R, Sanei B, Baradaran A, Spotin A, Bagherpour B, Darani HY. Genetic characterization of Echinococcus granulosus strains isolated from humans based on nad1 and cox 1 gene analysis in 
Isfahan, central Iran. J Helminthol 2018;92:696-702.

35. Spotin A, Gholami S, Nasab AN, Fallah E, Oskouei MM, Semnani $\mathrm{V}$, et al. Designing and conducting in silico analysis for identifying of Echinococcus spp. with discrimination of novel haplotypes: an approach to better understanding of parasite taxonomic. Parasitol Res 2015;114:1503-1509.

36. Bae JM. A suggestion for quality assessment in systematic reviews of observational studies in nutritional epidemiology. Epidemiol Health 2016;38:e2016014.

37. Anvari D, Sharif M, Sarvi S, Aghayan SA, Gholami S, Pagheh AS, et al. Seroprevalence of Toxoplasma gondii infection in cancer patients: a systematic review and meta-analysis. Microb Pathog 2019;129:30-42.

38. Saberi R, Sharif M, Sarvi S, Aghayan SA, Hosseini SA, Anvari D, et al. Is Toxoplasma gondii playing a positive role in multiple sclerosis risk? A systematic review and meta-analysis. J Neuroimmunol 2018;322:57-62.

39. Hosseininejad Z, Sharif M, Sarvi S, Amouei A, Hosseini SA, Nayeri Chegeni $\mathrm{T}$, et al. Toxoplasmosis seroprevalence in rheumatoid arthritis patients: a systematic review and meta-analysis. PLoS Negl Trop Dis 2018;12:e0006545.

40. Rahimi MT, Sarvi S, Daryani A, Sharif M, Ahmadpour E, Shokri A, et al. Application of multiplex PCR for the simultaneous detection of Taenia spp. from domestic dogs in the north of Iran. Helminthologia 2016;53:285-289.

41. Sadjjadi SM. Present situation of echinococcosis in the Middle East and Arabic North Africa. Parasitol Int 2006;55 Suppl:S197S202.

42. Schneider R, Gollackner B, Edel B, Schmid K, Wrba F, Tucek G, et al. Development of a new PCR protocol for the detection of species and genotypes (strains) of Echinococcus in formalin-fixed, paraffin-embedded tissues. Int J Parasitol 2008;38:1065-1071.

43. Khademvatan S, Majidiani H, Foroutan M, Hazrati Tappeh K, Aryamand S, Khalkhali HR. Echinococcus granulosus genotypes in Iran: a systematic review. J Helminthol 2019;93:131-138.
44. Cucher MA, Macchiaroli N, Baldi G, Camicia F, Prada L, Maldonado L, et al. Cystic echinococcosis in South America: systematic review of species and genotypes of Echinococcus granulosus sensu lato in humans and natural domestic hosts. Trop Med Int Health 2016;21:166-175.

45. Galeh TM, Spotin A, Mahami-Oskouei M, Carmena D, Rahimi MT, Barac A, et al. The seroprevalence rate and population genetic structure of human cystic echinococcosis in the Middle East: a systematic review and meta-analysis. Int J Surg 2018;51:39-48.

46. Yildiz K, Gurcan S. Prevalence of hydatidosis and fertility of hydatid cysts in sheep in Kirikkale, Turkey. Acta Vet Hung 2003;51: 181-187.

47. Alvarez Rojas CA, Romig T, Lightowlers MW. Echinococcus granulosus sensu lato genotypes infecting humans - review of current knowledge. Int J Parasitol 2014;44:9-18.

48. Elham M, Hassan B, Ghasem NA, Gholamreza R, Parviz S. Epidemiological study of hydatidosis in the dromedaries (Camelus dromedarius) of different regions of Iran. Asian Pac J Trop Biomed 2014;4:S148-S151.

49. Sharma M, Sehgal R, Fomda BA, Malhotra A, Malla N. Molecular characterization of Echinococcus granulosus cysts in north Indian patients: identification of G1, G3, G5 and G6 genotypes. PLoS Negl Trop Dis 2013; 7:e2262.

50. Casulli A, Interisano M, Sreter T, Chitimia L, Kirkova Z, La Rosa $\mathrm{G}$, et al. Genetic variability of Echinococcus granulosus sensu stricto in Europe inferred by mitochondrial DNA sequences. Infect Genet Evol 2012;12:377-383.

51. Sharbatkhori M, Fasihi Harandi M, Mirhendi H, Hajialilo E, Kia EB. Sequence analysis of cox 1 and nad1 genes in Echinococcus granulosus G3 genotype in camels (Camelus dromedarius) from central Iran. Parasitol Res 2011;108:521-527.

52. Parsa F, Fasihi Harandi M, Rostami S, Sharbatkhori M. Genotyping Echinococcus granulosus from dogs from Western Iran. Exp Parasitol 2012;132:308-312. 